\title{
Kan basıncı düşük hastalarda sakubitril/valsartan'ın etkinlik ve güvenliği değişir mi?
}

\author{
Dr. Mehdi Zoghi \\ Ege Üniversitesi Tıp Fakültesi, Kardiyoloji Anabilim Dalı, İzmir
}

Kalp yetersizliği (KY) hastalarında düşük sistolik kan basıncının (SKB) mortalite ile ilişkili verilerine baktığımızda; mortalitenin SKB $<90 \mathrm{mmHg}$ olanlarda 90-99 mmHg olanlara göre 1.5 kat daha fazla olduğu ve görülme sıklığının yeni tanı konulanlarda 3.17 olgu/100 hasta yılı olduğu tespit edilmiştir..$^{[1-3]}$

Konunun önemi nedeniyle PARADIGM-HF çalışmasının sonuçları da bu açıdan mercek altına alınmıştır. Bu çalışmada semptomatik hipotansiyonun görülme sıklığ1 sakubitril/valsartan grubunda $\% 14.0$ ve Enalapril grubunda \%9.2 (p<0.001), SKB $<90 \mathrm{mmHg}$ ve semptomatik hastaların oranı ise sırayla 2.7'e karş1 $\% 1.4(\mathrm{p}<0.001)$ olarak rapor edilmiştir (Şekil 1) (4). Çift kör periyodunda en az bir yan etki tespit edilen toplam 6922 hastada hipotansiyon oranı sakubitril/ valsartan'ın aleyhinde (\%17.6'e karş1 \%11.9) idi. ${ }^{[4,5]}$ Dolayısıyla PARADIGM-HF çalışmasının genelinde sakubitril/valsartan'ın söz konusu olumlu sonlanım noktaları açısından, gerek tedavi başlangıcında gerek sonrasındaki hipotansiyon görülmesinin irdelenmesini elzem kılmaktadır.

PARADIGM-HF çalışmasının run-in fazında Enalapril grubundaki 10.513 hastanın 136'sında (\%1.3'ü) hipotansiyon geliştiği) ve \%68'inin çalışmanın bir sonraki fazına devam edemediği bildirilmiştir (Şekil 1). Çalışmaya alınan hastaların bazal SKB değerleri ise LCZ696 (sakubitril/valsartan) grubunda $(\mathrm{n}=4187) 122 \pm 15 \mathrm{mmHg}$, Enalapril grubunda $(\mathrm{n}=4212) 121 \pm 15 \mathrm{mmHg}$ iken run-in fazında LCZ696 grubunda bulunan 9.419 hastanın \%2.4'ünde hipotansiyon saptanmıştır. Hastaların $\% 51$ 'i ise çalışma dışı kalmıştır. Randomizasyon sonrasında ortalama SKB farkı iki tedavi grubu arasında dördüncü ayda 4-6 mmHg iken sekizinci ayda ortalama SKB'nin LCZ696 grubunda $3.2 \mathrm{mmHg}$ daha düşük olduğu $(\mathrm{p}<0.001)$ bildirilmiştir. ${ }^{[2-5]}$ PARADIGM-HF' de tüm çalışma boyunca ortalama fark anlamlı $(\mathrm{p}<0.001)$ ve LCZ960 aleyhine -2.70
$(-3.07,-2.34) \mathrm{mmHg}$ olarak rapor edilmiştir. Sistolik $\mathrm{KB}<110 \mathrm{mmHg}$ olan hastalar daha genç olmakla birlikte iskemik etiyoloji, diyabet ve hipotansiyon hikayesi daha az idi (Tablo 1). ${ }^{[6,7]}$

Sakubitril/valsartan sonrası hipotansiyon hangi hastalarda görülür? Sorusuna yapılan ilk açıklamalar hipotansiyonun daha çok (vasküler volüm, dehidratasyon veya düşük sodyum alımı) RAAS'ı daha aktif olanlarda görüldüğü yönünde olmuştur. Orly Vardeny ve ark.$^{[5]}$ ise PARADIGM-HF çalışmasındaki hastaları ister run-in ister randomizasyon sonrası dönemde hipotansiyonu olan (ortalama SKB: $121.7 \pm 14.7 \mathrm{mmHg}$ ) ve olmayan (ortalama SKB: $128.6 \pm 16.9 \mathrm{mmHg}$ ) olarak iki grupta karşılaştırıldıklarında aşağıdaki sonuçlara varmışlardır:

1- Hipotansiyonu olanların demografik ve klinik bulguları ışı ğında daha yaşlı, çalışmanın tarama aşamasında NT-proBNP düzeyleri yüksek ve SKB, diyastolik KB, GFR düzeyleri ve sol ventrikül ejeksiyon fraksiyonlarının daha düşük olduğu tespit edilmiştir. Kan basıncını etkileyen ilaçlar aç1sından nitrat ve kalsiyum kanal blokeri kullanım oranı daha yüksek idi.

2- Tarama süreci öncesinde hedef dozlarının altında ACE-inhibitörü veya ARB kullananlarda hipotansiyon gelişme sıklığı daha fazla görülmüştür (\%4'e karş1 \%3; p=0.005).

3- Enalapril'in run-in periyodunda hipotansiyon gelişen hastaların üçte ikisi, sakubitril/valsartan'ın run-in periyodunda ise yaklaşık yarısı randomizasyon öncesi çalışma dışı kalmıştır. Yazarlar ayrıca bu verileri önceki KY çalışmaları ile de kıyasladıklarında PARADIGM-HF çalışmasındaki hipotansiyon oranının daha yüksek olmadığı sonucuna varmışlardır.

Yanitlanması gereken asıl soruya gelince Prof. Dr. Michael Böhm ve ark. PARADIGM-HF çalış- 


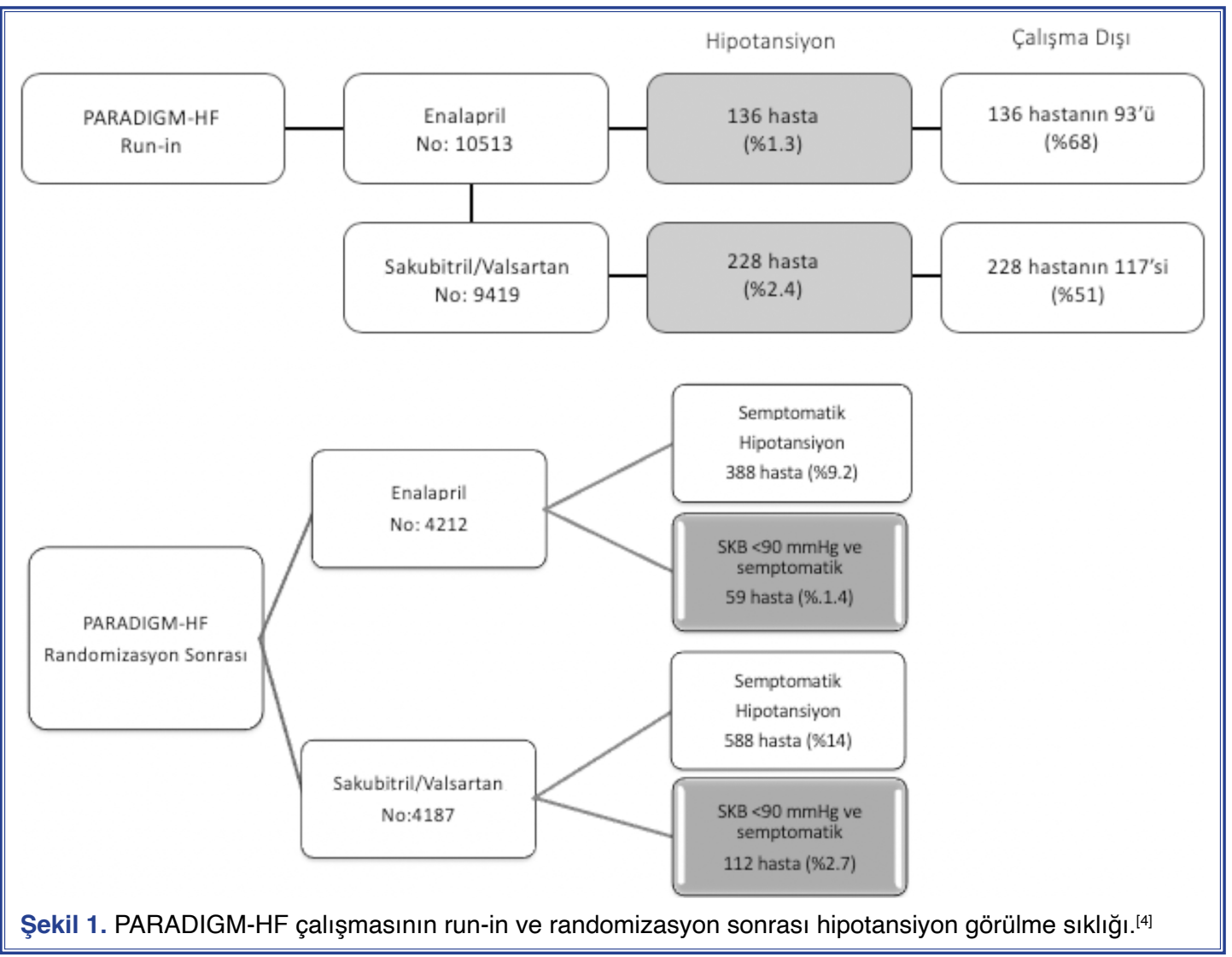

Tablo 1. PARADIGM-HF çalışmasındaki hasta özelliklerinin sistolik kan basınçlarına göre dağılımı

\begin{tabular}{|c|c|c|c|c|c|}
\hline & $\begin{array}{c}<110 \\
\mathrm{mmHg}\end{array}$ & $\begin{array}{c}110-<120 \\
\mathrm{mmHg}\end{array}$ & $\begin{array}{c}120-130 \\
\mathrm{mmHg}\end{array}$ & $\begin{array}{c}130-<140 \\
\mathrm{mmHg}\end{array}$ & $\begin{array}{l}>140 \\
\mathrm{mmHg}\end{array}$ \\
\hline Hasta sayısı & 1747 & 1931 & 2059 & 1477 & 1185 \\
\hline $\mathrm{SKB}(\mathrm{mmHg})$ & $102.18 \pm 3.7$ & $112.66 \pm 3.0$ & $122.76 \pm 3.0$ & $132.45 \pm 2.9$ & $147.73 \pm 9.1$ \\
\hline Yaş (yıl) & $61.30 \pm 12.0$ & $62.81 \pm 11.5$ & $64.34 \pm 11.1$ & $65.65 \pm 10.3$ & $65.83 \pm 10.8$ \\
\hline Hipertansiyon (\%) & 51.1 & 63.1 & 74.1 & 84.2 & 89.4 \\
\hline Enfarktüs (\%) & 41.5 & 47.4 & 42.6 & 42.8 & 40.9 \\
\hline Sakubitril/valsartan (\%) & 47.7 & 51.3 & 50.6 & 49.5 & 49.9 \\
\hline
\end{tabular}

Kaynak 7'deki tablo modifiye edilmiştir.

masındaki hastaları beş bazal SKB değerlerine göre ayırdı ve sonlanım noktaları açısından $(<110,110$ ile 120,120 ile $<130,130$ ile $<140$ ve $>140 \mathrm{mmHg}$ ) karşılaştırdılar. ${ }^{[7]}$ Kan basıncı grupları içerisinden SKB $<110 \mathrm{mmHg}$ referans olarak kabul edildiğinden (hazard ratio $=1$ ) $\mathrm{SKB}>140 \mathrm{mmHg}$ olanlar dışında aradaki SKB kategorilerinde tüm sonlanım noktalarında risk oranlarının daha düşük olduğu görülmektedir. SKB ve KY'ne bağlı hastaneye yatışlarda ise U şeklinde bir ilişki tespit edilmiş; Düşük SKB'li hastalarda ölüm riski (tüm nedenler ve kardiyovasküler) ve KY'ne bağlı hastanede yatış riski daha yüksek, $120 \mathrm{mmHg}$ üstündeki değerlerde ise her iki ölüm tipi için risk oranı düz bir çizgi çizmektedir. Ancak yaklaşık SKB <140 mmHg değerlerde KY'ne bağlı hastaneye yatışlarda tekrar risk artışı diğer bir deyişle U-benzeri bir orantı, söz konusudur. ${ }^{[7]}$ PARADIGM-HF çalışmasındaki SKB $<110 \mathrm{mmHg}$ olanlardan sakubitril/valsartan grubunda \%1.3 (13 hasta) ve Enalapril grubunda $\% 1$ (9 hasta) oranında ilaca devam etmemiştir. ${ }^{[7]}$ Sakubitril/valsartan grubundaki etkinlik düzeyinin KB düzeylerine ve hipotansiyona göre fark gösterip göstermediği konusuna gelince: 


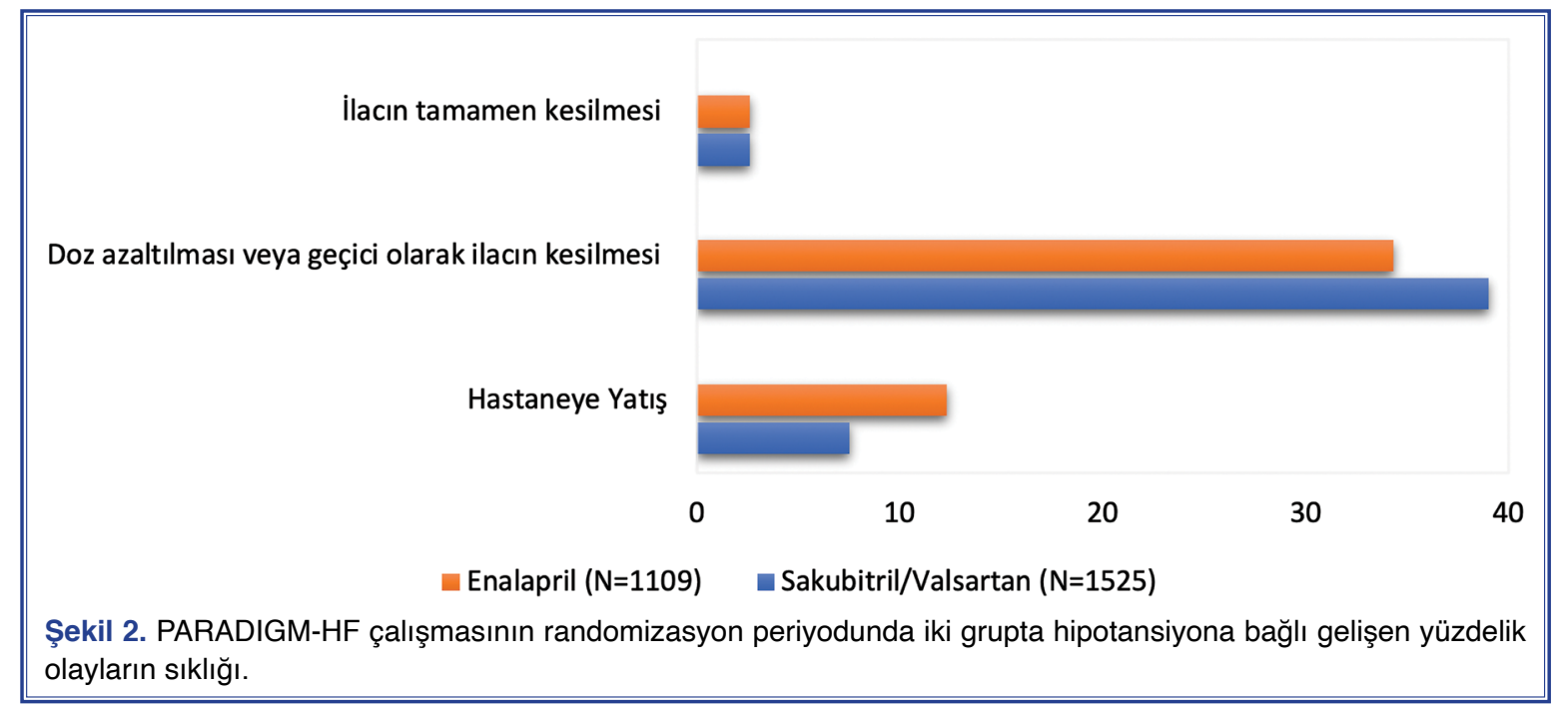

1- Hipotansiyona rağmen randomize edilenlerde sakubitril/valsartan yararı hipotansif olay yaşamayanlara benzer saptanmıştır (P interaction $>0.90$ ).

2- Randomizasyon periyodunda hipotansiyona bağlı gelişen olay açısından iki grup arasındaki fark anlamlı (Enalapril \%12.3, sakubitril/valsartan \%7.5, $\mathrm{p}<0.001$ ) olmakla birlikte bu durum ilacin birakılmasını nadiren gerektirmiştir. Doz azaltılması veya geçici olarak ilacın bırakılması sakubitril/ valsartan grubunda daha fazla iken (\%39'a karş1 \%34.3, $\mathrm{p}=0.014$ ) çalışma ilacın tamamen kesilmesi oranı iki grupta benzer bulunmuştur (Şekil 2).

3- Birincil sonlanım noktalarında sakubitril/valsartan tüm SKB kategorilerinde Enalapril'e göre risk azalması sağlamıştır (SKB-tedavi etkileşimi $\mathrm{P}=0.55){ }^{[5-7]}$

PARADIGM-HF çalışmasında run-in ve randomizasyon sonrasına bakılmaksızın sakubitril/valsartan'ın Enalapril'e kıyasla bildirilen olumlu klinik sonuçlarının düşük SKB açısından etkilenmediğini söylemek mümkündür. ${ }^{[8]}$ Ancak tedaviye sakubitril/valsartan'ın $\mathrm{SKB} \geq 100 \mathrm{mmHg}$ 'de başlanması, hipotansiyon geliştiğinde dozunun azaltılması, kullanılmakta olan antihipertansif ilaçların ve diüretiğin dozlarının yeniden düzenlenmesi önerilmektedir. Ayrıca artık kimlerde daha çok hipotansiyon riskinin gelişeceğini bildiğimize göre sakubitril/valsartan'a başlamadan önce hastanın sodyum ve volüm durumu dahil hipotansiyonun prediktörleri göz önünde tutulmalıdır. ${ }^{[9]}$

Hastaneye yatışından sonraki ilk gün ile 10. gün arasında akut dekompanze KY hastalarının karşılaştırıldığı PIONEER-HF çalışmasında ise randomizasyon sırasında medyan SKB 118 mmHg iken
$\mathrm{SKB}<110 \mathrm{mmHg}$ olanların siklı̆̆ $\% 23.4$ olarak bildirilmiştir. Veriler 1 şı ğında randomizasyon sonras1 SKB $<100 \mathrm{mmHg}$ oran1 1. haftada Enalapril grubunda \%13.3, sakubitril/valsartan grubunda \%22.3 iken 8 . haftada sirayla $\% 12.2$ ve $\% 15.6$ olarak rapor edilmiştir. Hipotansiyon nedeniyle çalışmayı erken bırakma oranları da her iki çalışma grubunda benzer (\%2.5) bildirilmiştir. Çalışmanın sonuçları itibariyle sakubitril/valsartan lehine olan NT-proBNP ve birleşik sekonder sonlanım noktaları açısından semptomatik hipotansiyon tespit edilenlerde, sakubitril/valsartan (\%15) ile Enalapril (\%12.7) arasında istatistiksel olarak anlamlı bir fark saptanmamıştır ( $p>0.05$, Göreceli risk: 1.18). ${ }^{[10]}$

\section{Sonuç olarak;}

Hipotansiyon, sakubitril/valsartan'da Enalapril'e göre daha fazla görülmekle birlikte ilacı bıraktırma konusunda oranlar benzer olmaktadır. Sakubitril/valsartan grubunda randomizasyon öncesi hipotansiyon gelişenlerdeki Enalapril'e göre olan olumlu etki hipotansiyon gelişmeyenlere göre benzerdir. Dolayısıyla hipotansiyon sakubitril/valsartan'ın başlanması için bir engel değildir. Düşük dozdan başlanılabilir ve hasta yakından takip edilmelidir.

\section{Kaynaklar}

1. Lee TT1, Chen J, Cohen DJ, Tsao L. The association between blood pressure and mortality in patients with heart failure. Am Heart J 2006;151:76-83.

2. Yi SW, Mok Y, Ohrr H, Yi JJ, Yun YD, Park J, Jee SH. Low systolic blood pressure and vascular mortality among more than 1 million Korean adults. Circulation 2016;133:2381-90.

3. Martín-Pérez M, Michel A, Ma M, García Rodríguez LA. Development of hypotension in patients newly diagnosed with heart failure in UK general practice: retrospective cohort and nested case-control 
analyses. BMJ Open 2019;9:e028750.

4. McMurray JJ, Packer M, Desai AS, Gong J, Lefkowitz MP, Rizkala $\mathrm{AR}$, et al. Angiotensin-neprilysin inhibition versus enalapril in heart failure. N Engl J Med. 2014;371:993-1004.

5. Vardeny O, Claggett B, Kachadourian J, Pearson SM, Desai AS, Packer M, et al. Incidence, Predictors, and Outcomes Associated With Hypotensive Episodes Among Heart Failure Patients Receiving Sacubitril/Valsartan or Enalapril: The PARADIGM-HF Trial (Prospective Comparison of Angiotensin Receptor Neprilysin Inhibitor With Angiotensin-Converting Enzyme Inhibitor to Determine Impact on Global Mortality and Morbidity in Heart Failure). Circ Heart Fail 2018;11:e004745.

6. Bruno RM, Taddei S. Sacubitril/valsartan and low blood pressure in heart failure with reduced ejection fraction. Eur Heart $\mathrm{J}$ 2017;38:1144-6.
7. Böhm M, Young R, Jhund PS, Solomon SD, Gong J, Lefkowitz MP, et al. Systolic blood pressure, cardiovascular outcomes and efficacy and safety of sacubitril/valsartan (LCZ696) in patients with chronic heart failure and reduced ejection fraction: results from PARADIGMHF. Eur Heart J 2017;38:1132-43.

8. Vardeny O, Claggett B, Packer M, Zile MR, Rouleau J, Swedberg K, et al. Efficacy of sacubitril/valsartan vs. enalapril at lower than target doses in heart failure with reduced ejection fraction: the PARADIGMHF trial. Eur J Heart Fail 2016;18:1228-34.

9. Fonseca C, Brito D, Ferreira J, Franco F, Morais J, Cardoso JSet al. Sacubitril/valsartan: A practical guide revisited. Rev Port Cardiol 2019;38:527-9.

10. Velazquez EJ, Morrow DA, DeVore AD, Duffy CI, Ambrosy AP, McCague K, et al. Angiotensin-Neprilysin Inhibition in Acute Decompensated Heart Failure. N Engl J Med 2019;380:539-48. 